\title{
MULHERES NA CIÊNCIA: UM ESTUDO DA PRESENÇA FEMININA NO CONTEXTO INTERNACIONAL
}

\author{
Josefa Martins da Conceição* \\ Maria do Rocio Fontoura Teixeira ${ }^{* *}$
}

\begin{abstract}
Resumo: Este artigo apresenta um levantamento do estado da arte da presença das mulheres na ciência e tem como objetivo resgatar suas participações no âmbito internacional, durante o período de 2007 a 2017. O estudo usou como metodologia artigos em formato digital, que puderam ser recuperados via internet, e livros eletrônicos e impressos. Foram utilizadas como expressões de busca "mulheres na ciência", "mulher e ciência", "mulheres cientistas", "gênero e ciência", "woman and science"; "women scientist"; "gender in science", "femme et sciencia", "mujeres y ciência", "mujeres cientistas" e "genre y ciência". Como fonte de coleta, foram utilizados dados das Bases Scopus, Jstor, Persée, Scielo, Scielo Livros e ProQuest Ebook Central. A partir do contexto histórico do tema, das leituras e análises realizadas, é possível afirmar que, apesar dos avanços do acesso à educação, da inserção das mulheres no espaço público e na ciência, os estudos ainda comprovam que - a despeito da crescente visibilidade do gênero feminino na ciência em algumas áreas, como a das ciências duras -, há uma forte resistência e luta para a conquista do espaço das mulheres na carreira científica.
\end{abstract}

Palavras-Chave: Mulheres na ciência. Mulheres cientistas. Gênero na ciência. Estado da arte.

\section{Introdução}

O mundo da ciência se estruturou historicamente em bases quase exclusivamente masculinas, ora excluindo as mulheres, ora negando as suas produções científicas, através de discursos e práticas nada neutros. Desse modo, é impossível falar sobre a presença das mulheres na Ciência sem falar sobre a história das mulheres. Sobre isso, é importante lembrar que essa história é recente, construída em meio a relações de poder, em um universo historicamente construído no masculino (SCHIENBINGER, 2001; PERROT, 2005; SOIHET,1997).

Esse território hegemonicamente masculino da Ciência não se deve ao fato de as mulheres serem menos capazes do que os homens, mas, sim, de terem sido condenadas ao silêncio e confinadas ao espaço privado, à esfera doméstica. Nesse sentido, de acordo com Cordeiro, (2013), apesar do passar dos anos, algumas ocupações que ainda apresentam dicotomias - a política, os negócios e a ciência - surgem como atividades masculinas,

\footnotetext{
* Universidade Federal do Rio Grande do Sul, Doutoranda do Programa de Pós-Graduação em Educação em Ciências: Química da Vida e Saúde da UFRGS.

** Universidade Federal do Rio Grande do Sul, Doutora em Educação em Ciências pela Universidade Federal do Rio Grande do Sul (UFRGS); professora permanente do Programa de Pós-Graduação em Educação em Ciências: Química da Vida e Saúde da UFRGS, Orientadora.
} 
enquanto que as atividades relacionadas ao ato do cuidar - as domésticas, a enfermagem e a educação - são de imediato relacionadas às atividades femininas. Eis o motivo da marginalização das mulheres do mundo científico. Apesar das dificuldades e desafios que as mulheres enfrentaram, e ainda enfrentam, para produzir ciência em um meio que foi construído de acordo com os parâmetros masculinos da moderna sociedade ocidental, elas, ainda assim, fizeram-no, e o fazem (BARBOSA E LIMA, 2013; YANNOULAS, 2013; PERROT, 2007; SAFFIOTI,1976).

No contexto deste estudo, entende-se ciência segundo a definição de Chassot (2017, p.36), de que a "Ciência pode ser considerada como uma linguagem construída pelos homens e pelas mulheres para explicar o nosso mundo natural". Sem a pretensão de ser completa, esta pesquisa do tipo estado da arte apresenta como características o recorte temático, o recorte temporal e o recorte espacial. O recorte temático refere-se à produção sobre as mulheres na ciência. $\mathrm{O}$ recorte temporal tem por objetivo fazer o mapeamento e a análise das publicações do período de 2007 a 2017. Como recorte espacial, têm-se os artigos científicos e os livros contidos na literatura internacional. Após a coleta do material, seguiram-se as etapas da leitura das produções, com elaboração de sínteses, análise e escrita das conclusões preliminares.

$\mathrm{O}$ estudo foi baseado nos artigos em formato digital, que puderam ser recuperados via internet, e livros eletrônicos e impressos. Foram utilizadas como expressões de busca "mulheres na ciência", "mulher e ciência", "mulheres cientistas", "gênero e ciência", "woman and science"; "women scientist"; "gender in science", "femme et sciencia", "mujeres y ciência", "mujeres cientistas" e "genre y ciência". Como fonte de coleta, foram utilizados dados das Bases Scopus, Jstor, Persée, Scielo, Scielo Livros e ProQuest Ebook Central, com vistas a assegurar um quadro substancial das investigações teóricas produzidas na temática.

Essa estratégia combinada de busca favoreceu a identificação de um corpus de 129 produções, entre 59 artigos publicados em 34 periódicos internacionais e 70 livros, sendo 38 deles em inglês, 25 em espanhol e 07 em francês. Esses dados apresentados na forma de quadros possibilitam afirmar que, no período estudado, a produção sobre a questão das mulheres na ciência, se não é abundante, também não pode mais ser considerada incipiente ou rara.

\section{Estado da arte: contexto internacional}

Os historiadores fizeram a historiografia do silêncio. Contudo, as mulheres nunca estiveram ausentes da história. Embora a historiografia oficial as tenha esquecido, elas 
participaram da construção do pensamento científico, e suas contribuições e realizações científicas são tão antigas quanto a ciência. Shienbinger (2001) afirma que a questão do gênero na Ciência passou a constituir uma área de especialidade dentro da história das ciências direcionada, por um lado, às mudanças que o feminismo trouxe para a ciência e, por outro, para se há uma forma feminina de fazer ciência. Nesse contexto, encontram-se trabalhos direcionados à exclusão, marginalização, invisibilidade, participação e biografias das mulheres na ciência, que buscam analisar a subordinação das mulheres aos homens nas civilizações ocidentais (SHIENBINGER, 2001, 2008; BLEIER, 1988; LONGINO,1987; BARBOSA, 2016).

No período de 2007 a 2017, foi possível verificar que a produção de artigos científicos e livros encontra-se distribuída em diversos países do Continente Europeu, América Latina, África e Ásia, com maior concentração em Portugal, Inglaterra e Estados Unidos, conforme a figura abaixo.

Figura 1 - Distribuição internacional da produção de artigos e livros

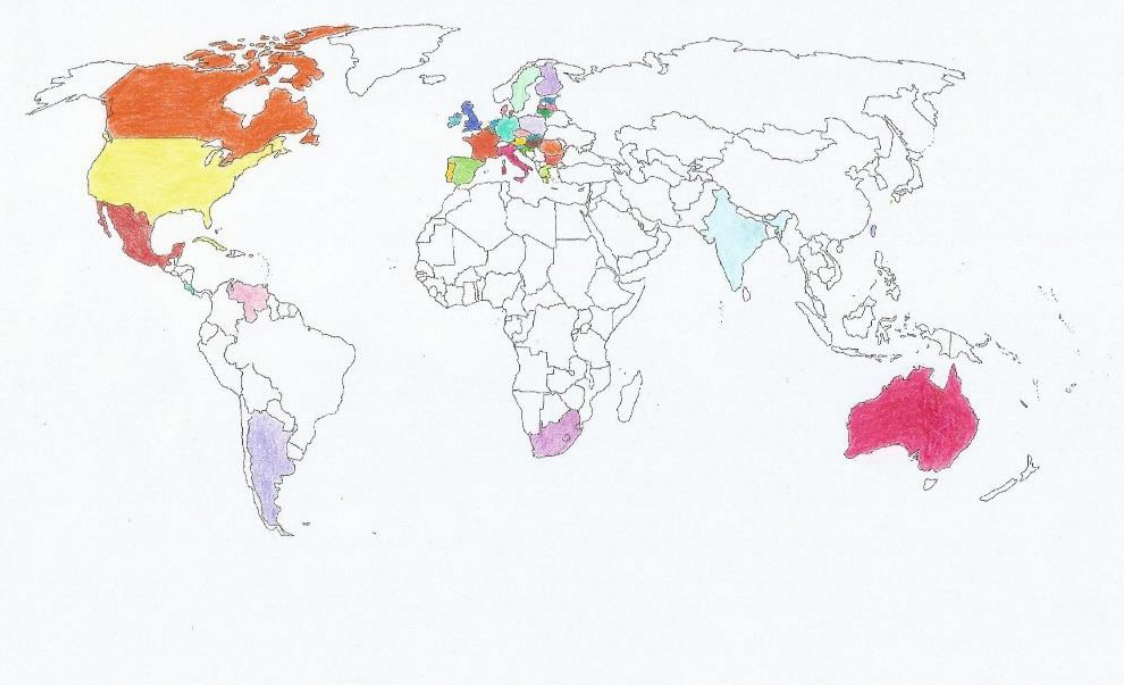

Fonte: As autoras, 2018.

\section{Artigos científicos internacionais}

Uma breve contextualização histórica do cenário internacional resgata alguns dos primeiros artigos publicados. A socióloga americana Rossi (1965) foi a primeira interessada em problematizar a questão das mulheres em carreiras científico-tecnológicas, ao publicar o 
primeiro artigo científico direcionado ao tema, "Women in science: Why so few? Social and psychological influences restrict womens's choice and pursuit of careers in science".

No texto, considerado marco no campo de gênero e ciência, Rossi questionou pela primeira vez a questão do pequeno número de mulheres fazendo ciência e discutiu a participação das mulheres trabalhando em atividades de Ciência e Tecnologia (C\&T) nos EUA nos anos de 1950 e 1960, concluindo que o baixo número de mulheres nas Engenharias e em algumas áreas das Ciências Naturais ocorreu devido a aspectos que passam pelo social e psicológico.

Posteriormente, a partir da década de 1990, a revista Science continuou publicando matérias direcionadas ao tema mulher e ciência. Em sua edição de 16 de abril de 1993, a Science publicou um número especial, apresentando o levantamento geral da situação das mulheres cientistas em diversos países. Nesse volume, foram publicados dois estudos de Barinaga (1993a), onde questiona se existe uma mulher com estilo próprio de realizar tarefas científicas, como executar pesquisas no laboratório e organizar atividades colaborativas. Nesse mesmo volume, Barinaga (1993b) abordou ainda como a comunidade cientifica funciona com a pequena participação feminina e uma maior participação masculina.

Nessa linha de pesquisa, a Science publicou o estudo das pesquisadoras Davis e White (1993) sobre os problemas que as mulheres enfrentam na carreira científica e na elaboração de pesquisas dentro de uma comunidade cientifica. No ano de 1994, a Science trouxe mais um estudo da pesquisadora americana Barinaga (1994) sobre pesquisadoras femininas, onde a autora comparou a produção cientifica de mulheres dos EUA, Grã-Bretanha, Japão, Alemanha, Itália, Portugal, Turquia, Filipinas, Índia e Suécia.

Ainda nesse contexto histórico internacional, a Revista Nature é outro periódico importante na divulgação da produção cientifica relativa às mulheres na ciência, tendo como meta servir à ciência e aos cientistas em todos os aspectos dos trabalhos de suas carreiras. Para esse fim, na década de 1990, dedicou atenção às mulheres na ciência a partir do v. 365 . Goodfield (1996) resgatou a obra de cunho histórico de Rossiter, na qual o crescimento e a afluência do período pós-segunda guerra, que poderiam ter dado lugar a cientistas de ambos os sexos, mais e melhor treinados, não beneficiaram os dois igualmente; na verdade, desencadearam a marginalização das mulheres.

A década pesquisada mapeou a produção científica sobre o tema em 34 periódicos científicos internacionais, sendo que a maior concentração dos artigos ocorre na Revista Ex æquo (Portugal), com 26 artigos, seguida da Revista Nature (Reino Unido), da Revista 
Science (Estados Unidos), da Centaurus and International Journal of History of Science and is Cultural Aspects (Itália), da Revista Mujeres con ciencia (Espanha), da Clio Femmes, Genre, Histoire e Revue Francophone Internationale de Recherche Infirmière, Travail, genre et sociétés (ambas da França), e da Revista Venezolana de estudios de la mujer (Venezuela).

Gráfico 1- Periódicos com maior concentração de artigos

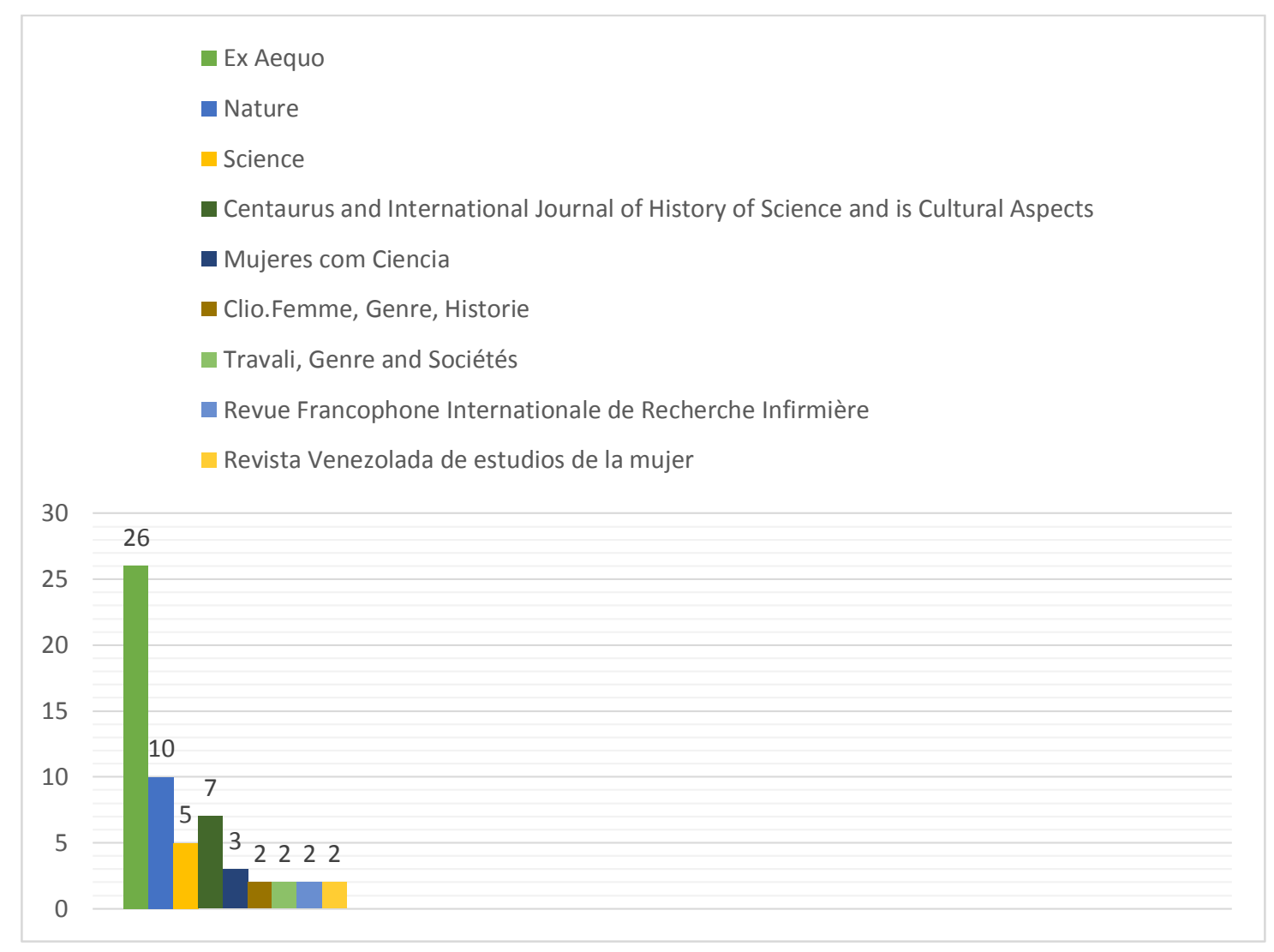

Fonte: As autoras, 2018.

Identificados os periódicos e recuperados os artigos, decidiu-se tomar como objeto de análise os 05 tipos de categorias recorrentes nos mesmos: Biografias; História das mulheres, dos seus silêncios e invisibilidade na ciência; Questões feministas e gênero na ciência; Carreira e participação na ciência; Empoderamento e teto de vidro. Contextualizadas no início de cada análise, essas categorias apresentam-se relevantes para o entendimento do que se propõe estudar, conforme o texto a seguir.

\subsection{Biografias}

A biografia é uma abordagem bastante utilizada nessa temática. De acordo com Shienbinger (2001, p.55), “em 1405, Christine de Pizan, tida como a primeira mulher a viver 
de sua pena, indagava se as mulheres haviam feito contribuições originais nas artes e nas ciências". Ainda de acordo com Shienbinger (2001), a obra de Pizan foi precedida e seguida por diversas enciclopédias de mulheres famosas. A primeira delas foi "De Mulieribus Claris", de autoria de Boccaccio, em 1374, apresentando curtas biografias de 106 mulheres, na maioria, rainhas (reais e míticas) do mundo antigo.

Tratando ainda sobre enciclopédias, Shienbinger (2001) resgatou o francês Ménage, que, em 1690, publicou uma enciclopédia de mulheres destacadas na filosofia antiga e moderna como parte de sua proposta para a admissão de mulheres na Académie Française. Por fim, evidenciou o astrônomo Lalande (1786), que publicou “Astronomy for Ladies", a primeira enciclopédia devotada exclusivamente à história das conquistas das mulheres nas Ciências Naturais.

Para Soihet (2003), no decorrer do tempo, as historiadoras e historiadores, empenhados em recuperar o passado feminino, encontraram como uma das principais dificuldades a ausência das mulheres nos arquivos e documentos da história oficial. Elas, as mulheres, enquanto isso, produziam e registravam suas histórias de modo particular, assumiam o papel de guardiãs das suas próprias memórias. Restava torná-las públicas, através da história oral, das histórias de vida e das biografias.

No recorte de tempo desta pesquisa, algumas mulheres que se dedicaram à ciência têm suas biografias abordadas nos artigos que seguem:

Tabela 1 - Delimitação dos artigos publicados na temática da Biografia

\begin{tabular}{ccc}
\hline ANO & $\begin{array}{c}\mathbf{N}^{\mathbf{0}} \text { DE } \\
\text { ARTIGOS }\end{array}$ & $\begin{array}{c}\mathbf{N}^{\mathbf{0}} \text { DE } \\
\text { AUTORES }\end{array}$ \\
\hline $\mathbf{2 0 0 7}$ & 01 & 01 \\
$\mathbf{2 0 0 9}$ & 01 & 01 \\
$\mathbf{2 0 1 3}$ & 01 & 01 \\
$\mathbf{2 0 1 4}$ & 01 & 01 \\
$\mathbf{2 0 1 5}$ & 01 & 01 \\
$\mathbf{2 0 1 6}$ & 01 & 01 \\
$\mathbf{2 0 1 7}$ & 03 & 05 \\
TOTAL & $\mathbf{0 9}$ & $\mathbf{1 1}$ \\
\hline
\end{tabular}

Fonte: As autoras, 2018.

Do total dos trabalhos resgatados, 09 deles trazem como temática de estudo a perspectiva da biografia. O artigo de Chervin (2007), ao resgatar a biografia de Marie Curie, explica por que a figura dessa cientista, um dos grandes nomes da história da ciência, é, ao mesmo tempo, a memória social da figura da mulher, capaz de abrir caminhos e incentivar outras mulheres a fazer ciência. O artigo de Queiroz (2014), por exemplo, traz à discussão a 
vida e a vasta obra de Mary Shelley (a autora de Frankenstein), mulher independente, determinada, inovadora, de cultura invulgar, que não se conformou com o papel imposto às mulheres da sua época, mas que, por muito tempo, ficou invisível na História.

3.2 História das mulheres, dos seus silêncios e invisibilidade na ciência

Esse é um campo da historiografia que, ao longo dos séculos, ficou relegado à invisibilidade e ao silêncio. Algumas historiadoras optaram por voltar no tempo e seguiram seus passos, buscando-as nos silêncios da História. Davis (1997), Perrot (2001, 2005) e Farge (2011) destacam-se como pioneiras nesse tipo de abordagem no plano internacional.

Na década de 1980, os estudiosos franceses Duby e Perrot, (2000) revelaram as mulheres como sujeitos da História, que têm voz, apesar do silêncio que lhes foi imposto por muito tempo. Para Perrot (2005), a dificuldade da História das mulheres deve-se, inicialmente, ao apagamento dos seus traços, tanto públicos quanto privados.

Acerca desse tema, foram encontrados os seguintes resultados:

Tabela 2 - Delimitação dos artigos publicados na temática da História das mulheres, dos seus silêncios e invisibilidade na ciência

\begin{tabular}{ccc}
\hline ANO & $\begin{array}{c}\mathbf{N}^{\mathbf{0}} \text { DE } \\
\text { ARTIGOS }\end{array}$ & $\begin{array}{c}\mathbf{N}^{\mathbf{0}} \text { DE } \\
\text { AUTORES }\end{array}$ \\
\hline $\mathbf{2 0 1 2}$ & 03 & 03 \\
$\mathbf{2 0 1 3}$ & 05 & 05 \\
$\mathbf{2 0 1 4}$ & 03 & 04 \\
TOTAL & $\mathbf{1 1}$ & $\mathbf{1 2}$ \\
\hline
\end{tabular}

Fonte: As autoras, 2018.

Dos 11 artigos publicados entre 2012 e 2014, selecionou-se um de cada ano. Eller (2012) traz à discussão as dificuldades enfrentadas pelas mulheres americanas que optam pela Engenharia, tais como lhes serem negadas posições de comando devido a superstições antimulher em minas e em navios, ou ainda serem ignoradas para trabalhos de campo, simplesmente por serem mulheres. Até o ano do estudo, o autor revela que menos de cinco por cento dos títulos de licenciatura em Engenharia foram concedidos às mulheres.

O artigo de Shen (2013) revela o preconceito sofrido pela estudante Lynne Kiorpes, no início da década de 1970, ao ingressar no curso de Engenharia e se defrontar com uma turma masculina. A autora comenta que tal situação já não é tão frequente nos tempos atuais. Contudo, o viés da misoginia ainda persiste. O artigo de Wang (2014) traz o resultado de uma pesquisa que verificou como as mulheres cientistas e tecnólogos de 03 universidades 


\section{\#tear}

nacionais de Taiwan moldam sua subjetividade de gênero no contexto social da tecnologia. Como resultado, a autora afirma que o discurso de sucesso das mulheres cientistas e tecnólogas pesquisadas deixou claro o cruzamento das fronteiras de gênero e autoempoderamento instigados pelo interesse pessoal, apoio familiar e apoio social das universidades.

\subsection{Questões feministas e gênero na ciência}

O movimento feminista do século XIX reivindicava às mulheres o direito ao voto, ao estudo, à herança, à propriedade e ao trabalho, direitos esses até aquele momento conferidos apenas aos homens. Após a conquista desses direitos, surgiram novas reivindicações, entre elas, os estudos de gênero como categoria de análise das relações sociais em suas produções e discussões. De acordo com Lopes (2006), "os termos conjugados gender and science apareceram pela primeira vez em 1978, como o título de um artigo em que Evelyn Fox Keller os utilizou para criticar a ciência sempre ligada ao masculino". Até a década de 1980, sobrevivia com força a dualidade entre sexo e gênero, sendo o primeiro para a natureza, e o segundo, para a cultura.

Uma das feministas que mais abalou essa concepção, trazendo novas perspectivas para os estudos de gênero, foi a historiadora estadunidense Scott (1995). Em suas obras, a autora defende o caráter relacional das definições de feminino e masculino, ao passo que rejeita a noção de determinismo biológico. Destaca o gênero como categoria analítica, tais como as de raça e classe, que promoveram a inclusão dos oprimidos na história, como também possibilita a análise do significado e da natureza da sua opressão e a compreensão acadêmica acerca das desigualdades.

Tabela 3 - Delimitação dos Artigos publicados na temática das questões feministas e gênero na ciência

\begin{tabular}{ccc}
\hline ANO & $\begin{array}{c}\mathbf{N}^{\mathbf{0}} \text { DE } \\
\text { ARTIGOS }\end{array}$ & $\begin{array}{c}\mathbf{N}^{\mathbf{0}} \text { DE } \\
\text { AUTORES }\end{array}$ \\
\hline $\mathbf{2 0 1 0}$ & 01 & 01 \\
$\mathbf{2 0 1 1}$ & 04 & 04 \\
$\mathbf{2 0 1 2}$ & 02 & 02 \\
$\mathbf{2 0 1 3}$ & 01 & 01 \\
$\mathbf{2 0 1 4}$ & 02 & 04 \\
$\mathbf{2 0 1 5}$ & 02 & 06 \\
$\mathbf{2 0 1 6}$ & 04 & 08 \\
$\mathbf{2 0 1 7}$ & 02 & 02 \\
TOTAL & $\mathbf{1 8}$ & $\mathbf{2 8}$ \\
\hline
\end{tabular}

Fonte: As autoras, 2018. 


\section{\#tear}

É possível visualizar, na tabela 3, a existência de 18 artigos com uma concentração dessa produção nos anos de 2011 e 2016, fato que justifica a análise dos artigos publicados em ambos. O trabalho de Schienbinger e Schraudner (2011) aborda as inovações de gênero como potencial a ser utilizado nas décadas vindouras, que exigirão colaborações interdisciplinares entre gêneros, especialistas, cientistas e engenheiros, refletindo sobre o potencial do gênero.

O artigo de Klanovicz (2011) examina a participação de mulheres nos cursos de Engenharia no Sul do Brasil. A autora traz o histórico sobre as entradas de mulheres em diferentes áreas de Engenharia em universidades públicas nos estados do Paraná e de Santa Catarina.

O trabalho de Santos e Carvalho (2016) destaca as contribuições da História das mulheres e da História do gênero para a renovação da ciência histórica. O artigo de Sarant (2017), por sua vez, analisa como a Arábia Saudita passou a investir na educação de meninas e mulheres. Em 1970, apenas 2\% das mulheres sauditas eram alfabetizadas. Já em 2017, esse percentual alcançou 92\% das mulheres. De acordo com o Fórum Econômico, afirma a autora, a Arábia Saudita é o quinto país do mundo em termos de investimento na equidade de gênero educacional.

\subsection{Carreira e participação na ciência}

A perspectiva sociológica dos estudos que focam os aspectos da carreira, da participação e das contribuições das mulheres na ciência apresenta-se como um dos maiores interesses para os pesquisadores, conforme afirma Leta (2014). Nessa linha, destacam-se dois estudos pioneiros, ambos publicados na Nature: o primeiro de Mead e Métraux, (1957), e o segundo de Rossi (1965).

Tabela 4 - Delimitação dos artigos publicados na temática carreira e participação na ciência

\begin{tabular}{ccc}
\hline ANO & $\begin{array}{c}\mathbf{N}^{\mathbf{0}} \mathbf{D E} \\
\text { ARTIGOS }\end{array}$ & $\begin{array}{c}\mathbf{N}^{\mathbf{0}} \mathbf{D E} \\
\text { AUTORES }\end{array}$ \\
\hline $\mathbf{2 0 1 0}$ & 01 & 02 \\
$\mathbf{2 0 1 1}$ & 02 & 05 \\
$\mathbf{2 0 1 2}$ & 03 & 07 \\
$\mathbf{2 0 1 4}$ & 04 & 09 \\
$\mathbf{2 0 1 5}$ & 03 & 05 \\
$\mathbf{2 0 1 6}$ & 02 & 04 \\
$\mathbf{2 0 1 7}$ & 03 & 04 \\
TOTAL & $\mathbf{1 8}$ & $\mathbf{3 6}$ \\
\hline
\end{tabular}

Fonte: As autoras, 2018. 
No campo dos estudos da temática representada acima, formada por 18 artigos, destaca-se o trabalho de Palhaci et al (2012), que sugere novas formas de pensar sobre as mulheres na ciência e campos de tecnologia, com base em pesquisas anteriores. $\mathrm{O}$ artigo de Neale e White (2016) analisa o contexto das mudanças na educação das mulheres, discutindo a questão da carreira na ciência. O trabalho de Marchant (2017) estuda o contexto do campo científico, onde grande parte dos cientistas masculinos compartilham o conhecimento entre si, perpetuando, de certa forma, a exclusão das mulheres cientistas.

\subsection{Empoderamento e teto de vidro}

O empoderamento feminino é a consciência coletiva, expressa por ações, para fortalecer as mulheres e desenvolver a equidade de gênero, (DALLER 2010; SCHMITZ e TRAMONTINA, 2017). Já a expressão teto de vidro refere-se a uma barreira invisível que impede a promoção de um indivíduo qualificado em um ambiente de trabalho por causa de gênero, raça ou etnia. No que se refere às mulheres na ciência, a explicação para esse fenômeno é puramente cultural. As mulheres recebem uma educação tradicional totalmente voltada para as questões sociais, direcionadas para assuntos da vida e da educação dos filhos. A educação é recheada de estereótipos para que as mulheres se dediquem a cuidar de pessoas, e não se direcionem à Ciência e Tecnologia (PONTELO, 2015).

Tabela 5 - Delimitação dos artigos publicados na temática do empoderamento e teto de vidro

\begin{tabular}{ccc}
\hline ANO & $\begin{array}{c}\mathbf{N}^{\mathbf{0}} \text { DE } \\
\text { ARTIGOS }\end{array}$ & $\begin{array}{c}\mathbf{N}^{\mathbf{0}} \text { DE } \\
\text { AUTORES }\end{array}$ \\
\hline $\mathbf{2 0 0 8}$ & 01 & 01 \\
$\mathbf{2 0 1 2}$ & 01 & 03 \\
$\mathbf{2 0 1 6}$ & 01 & 01 \\
TOTAL & $\mathbf{0 3}$ & $\mathbf{0 5}$ \\
\hline
\end{tabular}

Fonte: As autoras, 2018.

O teto de vidro é assunto dos artigos de Laufer (2008), que tratam do empoderamento das mulheres a partir de uma pesquisa que ressalta os avanços na conscientização sobre a igualdade de gênero, reafirmação e legitimação da identidade. Moskvitcho (2015) trata sobre essa questão, trazendo as dificuldades das cientistas que, segundo a autora, integram a minoria das minorias, trabalhando na Física nos países em desenvolvimento.

Por sua vez o, trabalho de Fremigacci, Gobillon e Roux (2016) discutem as diferenças no posicionamento de mulheres e homens no serviço público e em escalas salariais. Um 
posicionamento sistematicamente menos favorável das mulheres manifestaria um chamado fenômeno de "teto de vidro" na função pública. Para estudar essa possibilidade, o artigo aplica um método recente de medir desigualdades entre homens e mulheres.

\section{Livros internacionais}

O histórico da produção de livros direcionados às mulheres na ciência resgata a obra de autoria de Rebière (1897), resultado da primeira conferência sobre mulheres e ciência, organizada pelos saint-simonianos e realizada em Paris no ano de 1894. O autor incluía as mulheres como "cientistas profissionais", assim como as amadoras e aquelas patrocinadoras, cujas contribuições haviam ajudado "o progresso da ciência". No prefácio, escreveu: "Estamos reunidos pela primeira vez com variadas opiniões sobre duas questões: as mulheres são capazes de fazer ciência. E como essas mulheres praticam ciência” (REBIÈRE, 1897, p. IX).

Mozans (1913) discorre sobre os muitos desenvolvimentos da ciência ao longo da História. Sua obra objetivou aumentar as oportunidades de educação e carreira para as mulheres interessadas em ciência, e que essas se envolvessem cada vez mais e obtivessem uma posição respeitada no campo científico.

Ainda segundo Shienbinger (2001, p.57-58), esse livro "conclamava as mulheres a juntarem-se ao empreendimento cientifico e desencadearem as energias da metade da humanidade". É considerada a obra inicial no despertar para a literatura sobre mulher na ciência, cujo crescimento foi acontecendo, ainda de forma incipiente, nos anos 1960 até os anos 1970.

Merece destaque o interesse e a participação da UNESCO, a partir dos anos 1990, na realização de estudos, pesquisas e promoção de atividades. O mapeamento quantitativo dos livros publicados na literatura internacional no período proposto neste estudo é descrito a seguir.

Tabela 6 - Delimitação dos livros publicados

\begin{tabular}{cccc}
\hline ANO & $\begin{array}{c}\text { LIVROS EM } \\
\text { INGLÊS }\end{array}$ & $\begin{array}{c}\text { LIVROS EM } \\
\text { ESPANHOL }\end{array}$ & $\begin{array}{c}\text { LIVROS EM } \\
\text { FRANCÊS }\end{array}$ \\
\hline $\mathbf{2 0 0 7}$ & - & 01 & 03 \\
$\mathbf{2 0 0 8}$ & 03 & 01 & - \\
$\mathbf{2 0 0 9}$ & 01 & 02 & - \\
$\mathbf{2 0 1 0}$ & 11 & 04 & - \\
$\mathbf{2 0 1 1}$ & 02 & 03 & - \\
\end{tabular}




\begin{tabular}{cccc}
$\mathbf{2 0 1 2}$ & 01 & 02 & 02 \\
$\mathbf{2 0 1 3}$ & - & 03 & - \\
$\mathbf{2 0 1 4}$ & 06 & 06 & - \\
$\mathbf{2 0 1 5}$ & 03 & - & - \\
$\mathbf{2 0 1 6}$ & 03 & 01 & - \\
$\mathbf{2 0 1 7}$ & 08 & 02 & 02 \\
TOTAL & $\mathbf{3 8}$ & $\mathbf{2 5}$ & $\mathbf{0 7}$ \\
\hline
\end{tabular}

Fonte: As autoras, 2018.

Gráfico 2 - Livros internacionais que tratam sobre mulheres na ciência

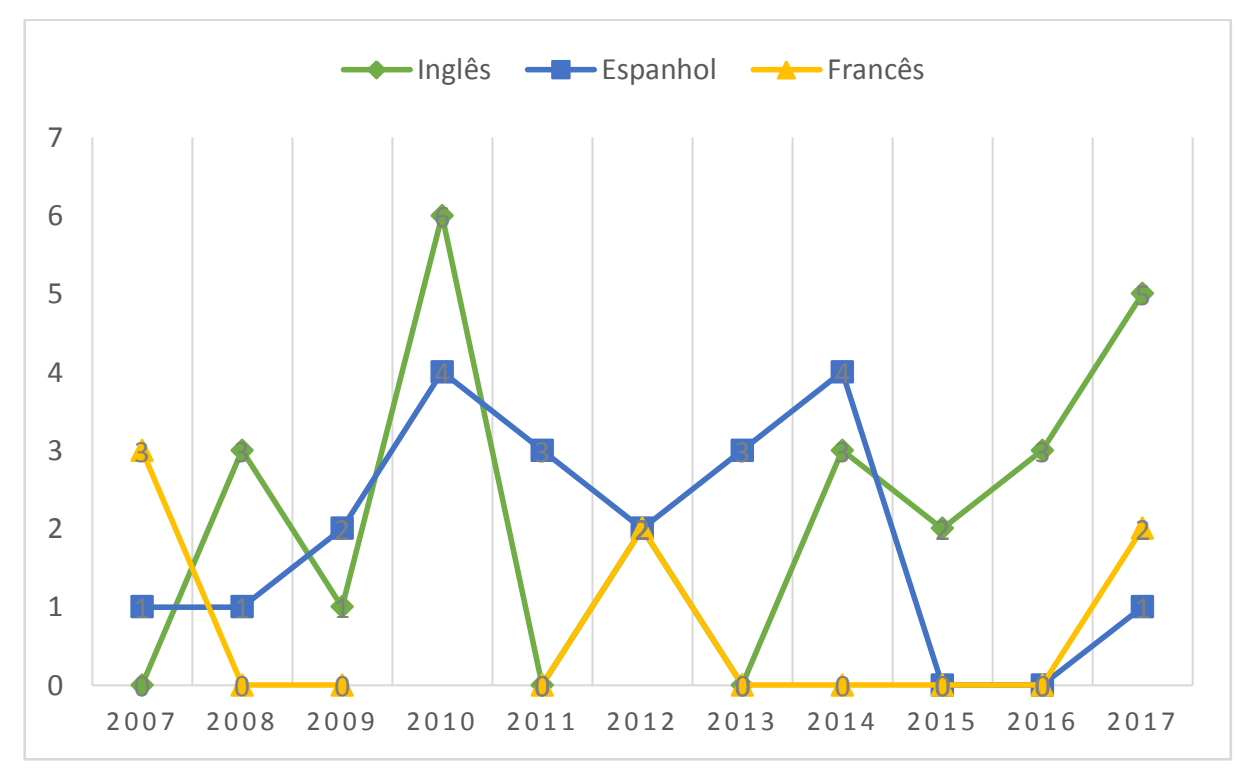

Fonte: As autoras, 2018.

Na distribuição da quantidade dos livros pelo ano e pelo idioma, conforme o gráfico 2, pode-se concluir que há maior concentração de publicações na língua inglesa nos anos de 2010 e 2017. Desse grupo, dois títulos se destacam pela singularidade no tratamento dos assuntos, e foram selecionados para a análise que segue.

Des Jardins (2010) discute o complexo Madame Curie como um fenômeno que ultrapassa as explicações mais comuns, desde o acesso limitado ao treinamento profissional até a falta de recursos e revelações sobre as contribuições das mulheres para as ciências. Explorando as vidas de Jane Goodall, Rosalind Franklin, Rosalyn Yalow, Barbara McClintock, Rachel Carson e as mulheres do Projeto Manhattan, a autora considera suas histórias pessoais e profissionais em relação aos seus homólogos masculinos Albert Einstein, 


\section{\#tear}

Robert Oppenheimer e Enrico Fermi para demonstrar como a cultura de ciência de gênero molda os métodos, a estrutura e a experiência do trabalho.

Clinton (2017) enfatiza a vida e a carreira de 13 mulheres americanas que perseveraram diante da adversidade e ajudaram a moldar o país, às vezes através da fala, às vezes ficando sentada, às vezes cativando uma audiência. É uma obra para despertar as meninas e as jovens para as ciências.

\section{Considerações finais}

O estado da arte da produção científica internacional sobre as mulheres na ciência no período de dez anos, compreendido entre 2007 a 2017, mapeou 129 produções, distribuídas em 59 artigos publicados por autores de diversos países em 34 revistas internacionais, dentre elas, a Revista Nature e a Revista Science. Foram localizados 70 livros publicados sobre o tema, sendo 38 deles em inglês, 25 em espanhol e 07 em francês. $\mathrm{O}$ tema mais explorado pelos pesquisadores foi Gênero na Ciência e Questões Feministas, seguido pelo tema da Carreira e participação na Ciência. Há uma discrepância entre o número de publicações científicas assinadas pelos pesquisadores, ficando evidente que a maioria das autorias fica por conta das pesquisadoras.

Dos 59 artigos, destacam-se 18 que focam as Questões Feministas e Gênero na Ciência, seguidos por 18 artigos que tratam a temática da Carreira e participação na Ciência; 11 que se dedicam à temática da História das Mulheres, dos seus silêncios e invisibilidade na Ciência; 09 que tratam a temática da Biografia de mulheres que se destacaram na ciência ao longo do tempo; e 03 que chamam a atenção para a questão do Empoderamento e do Teto de Vidro na ciência, ratificando a necessidade da promoção de ações para fortalecer as mulheres e desenvolver a equidade de gênero através da equiparação.

Outro ponto que merece ser destacado refere-se à quantidade de artigos publicados por cada pesquisador. Entre os artigos analisados, seis autores publicaram dois artigos cada um, dentre eles, a física brasileira Barbosa, que publicou duas vezes no ano de 2015. A revista científica portuguesa Ex æquo desponta como o periódico que apresenta o maior número dos artigos publicados.

A partir do contexto histórico do tema e das leituras realizadas, é possível afirmar que, ao longo do tempo, houve avanços significativos no acesso à educação, na inserção das mulheres no espaço público e na ciência. No entanto, os estudos sinalizam que, apesar da crescente visibilidade do gênero feminino na ciência, em algumas áreas, especialmente a das 


\title{
\#tear
}

ciências duras, ainda há barreiras a serem transpostas pelas mulheres na luta para a conquista do seu espaço científico.

\section{WOMEN IN SCIENCE: A STUDY OF WOMEN'S PRESENCE IN THE INTERNATIONAL CONTEXT}

\begin{abstract}
This article consists of the state of the art of women in science and aims to recover the presence and participation of women in the international scope during the period from 2007 to 2017. From the historical context of the theme, from the readings and analyzes carried out, it is possible affirm that, despite advances in access to education, women's inclusion in public space and science, studies still prove that - despite the increasing visibility of women in science in some areas, such as hard sciences - there is a strong resistance and struggle for the conquest of women's space in scientific careers.
\end{abstract}

Keywords: Women in science. Women scientists. Gender in science. State of art.

\section{Referências}

BARBOSA, L. A. L. Os homens são naturalmente melhores em matemática do que as mulheres: um discurso que persiste. Revista Diversidade e Educação: Gênero e Ciência, Porto Alegre, v. 4, n. 8, p.33-41, jul./dez, 2016. Disponível em: <https://periodicos.furg.br/divedu/article/view/6738/4425>. Acesso em: 11 dez. 2017.

BARBOSA, M. C.; LIMA, B. S. Mulheres na Física do Brasil: Por que tão poucas? E por que tão devagar? In: YANNOULAS, S. C. (Coord). Trabalhadoras: análise da feminização das profissões e ocupações. Brasília: Editorial Abaré, 2013. Disponível em:

$<$ http://www.oitcinterfor.org/sites/default/files/file_publicacion/trabalhadoras.pdf $>$. Acesso em: 13 set. 2017.

BARINAGA, M. Is There a 'Female Style' in Science? Science, Washington, v. 260, issue 5106, p. 384-391, apr., 1993a. Disponível em:

<http://science.sciencemag.org/content/260/5106/384>. Acesso em: 13 dez. 2017.

Feminists Find Gender Everywhere In Science. Science, Washington, v. 260, issue 5106, p. 392-393, apr., 1993b. Disponível em: <http://science.sciencemag.org/content/260/5106/392>. Acesso em: 13 dez. 2017.

. Surprises Across the Cultural Divide. Science, Washington, v. 263, issue 5152, p. 1468-1472, mar., 1994. Disponível em: <http://science.sciencemag.org/content/sci/263/5152/1467.full.pdf > . Acesso em: 13 dez. 2017.

BLEIER, R. Science and Gender: A Critique of Biology and its Theories on Women. New York: Pergamon Press, 1988. 
CHASSOT, Á. I. A ciência é masculina?: É, sim senhora! São Leopoldo, RS: Ed. Unisos, 2017.

CHERVIN, J. Marie Curie, le spectre des figures. Communication \& Languages, Paris: Presses Universitaires de France, n. 152, p.55-67, 2007. Disponível em: <http://www.persee.fr/doc/colan_0336-1500_2007_num_152_1_4657>. Acesso em: 14 dez. 2017.

CLINTON, C. She Persisted: 13 American Women Who Changed the World. Nova York: Philomel Books, 2017.

CORDEIRO, M. D. Mulheres e ciência. $2^{\circ}$ Simpósio de Integração Científica e Tecnológica do Sul Catarinense - SICT-Sul. Revista Técnico-Científica do IFSC, 2013, Santa Catarina, v. 2, n. 2 - II SICT - Sul. Disponível em:

< https://periodicos.ifsc.edu.br/index.php/rtc/article/view/1468/858>. Acesso em: 21 fev. 2018.

DALLER, V. L. O. O empoderamento da mulher e a igualdade de gênero: Coopergênero uma política pública de cooperativismo. Coletânea de artigos apresentados no Encontro Brasileiro de Pesquisadores em Cooperativismo (EBPC), 1, 2010, Brasília. Disponível em: $<$ http://docplayer.com.br/29985483-Titulo-o-empoderamento-da-mulher-e-a-igualdade-degenero-coopergenero-uma-politica-publica-de-cooperativismo-autor-daller-v-l-o.html> . Acesso em: 25 fev. 2018.

DAVIS, N. Z. Nas Margens: três mulheres do século XVII. São Paulo: Companhia das Letras, 1997.

DAVIS, L. I.; WHITE, A. M. Women in Biomedicine. Science, Washington, v. 262, issue 5142, p. 1954-1955, 1993. Disponível em:

<http://science.sciencemag.org/content/262/5142/1954.3>. Acesso em: 13 dez. 2017.

DES JARDINS, J. The Madame Curie Complex: the hidden history of women in Science. New York: The Feminist Press at Cuny, 2010.

DUBY, G.; PERROT, M. Historia de las Mujeres en Occidente. Madri: Taurus Ediciones, 1991. Tomo 5, El Siglo XX. Disponível em:

< https://dialnet.unirioja.es/servlet/libro?codigo=11809\#volumen29771 >. Acesso em: 03 out. 2017.

ELLER, T. Publicity, Recruitment and History: Society of Women Engineers. Centaurus and International Journal of History of Science and is Cultural Aspects, Nova Jersey: Wiley Job Network, v, 54, issue 4, p. 299-304, nov., 2012. Disponível em: <http://onlinelibrary.wiley.com/doi/10.1111/j.1600-0498.2012.00275.x/pdf>. Acesso em: 03 out. 2017.

FARGE, A. Lugares da história. São Paulo: Autêntica, 2011.

FREMIGACCI, F.; GOBILLON, L.; ROUX, S. Égalité professionelle entre les hommes et les femmes: des plafonds de verre dans la fonction publique? Economie et Statistique, Paris, n. 


\section{\#tear}

488-489, p. 97-121, 2016. Disponível em: <http://www.persee.fr/doc/estat_03361454_2016_num_488_1_10714>.Acesso em: 03 out. 2017.

GOODFIELD, J. Invisible strangers. Nature, Londres, v. 380, mar., p.306-307, 1996.

Disponível em: <https://www.nature.com/articles/380306a0.pdf>. Acesso em: 13 dez. 2017.

KLANOVICZ, L. R. F. Historia, género e ciéncia: Mulheres engenheiras no sul do brasil.

Revista venezolana de estudios de la mujer, Caracas, v.16, n. 37, jul.-dic., p.105-122, 2011. Disponível em: <http://saber.ucv.ve/ojs/index.php/rev_vem/article/view/2006>. Acesso: 03 out. 2017.

KELLER, E. F. Gender and Science. In: HARDING, S.; HINTIKKA, M. B. Discovering Reality. Synthese Library, v. 161, p. 187-205, 2003. Disponível em: $<$ https://link.springer.com/chapter/10.1007\%2F978-94-010-0101-4_11\#citeas>. Acesso: 05 dez. 2017.

LAUFER, J. Les politiques des entreprises em matiére de plafond de verre. Santé, Societé et Solidarité, Paris, n. 1, p. 49-57, 2008.

Disponível em: <http://www.persee.fr/doc/oss_1634-8176_2008_num_7_1_1252>. Acesso em: 11 nov. 2017.

LETA, J. Mulheres na ciência brasileira: desempenho inferior? Revista Feminismos, Salvador, v. 2, n.3, p.139-152, set./dez., 2014. Disponível em: <http://www.feminismos.neim.ufba.br/index.php/revista/article/viewFile/129/131>. Acesso em: 15 nov. 2017.

LONGINO, H. Can there be a feminist science? Hypatia: A Journal of Feminist Philosophy, São Francisco, v. 2, issue 3, special issue, p. 51-64, set., 1987. Disponível em: <https://onlinelibrary.wiley.com/doi/pdf/10.1111/j.1527-2001.1987.tb01341.x>. Acesso em: 11 nov. 2017.

LOPES, M. M. Sobre convenções em torno de argumentos de autoridade. Cadernos Pagu, Campinas, v. 27, p. 35-61, jul./dez., 2006. Disponível em:

<http://www.scielo.br/pdf/cpa/n27/32138.pdf>. Acesso em: 11 nov. 2017.

MARCHANT, J. Male scientists share more — but only with other men. Scientific American. Nature, Washington, oct., 2017. Disponível em:

$<$ https://www.scientificamerican.com/article/male-scientists-share-more-but-only-with-othermen/>. Acesso em: 28 out. 2017.

MEAD, M.; MÉTRAUX, R. Image of the scientist among High-School Students. Science, Washington, v. 126, issue 3270, p. 384-390 aug., 1957. Disponível em: <http://science.sciencemag.org/content/126/3270/384>. Acesso em: 28 out. 2017.

MOSKVITCHO, K. Developing world: The minority minority. Nature, Londres, v. 519, issue 7541, p.20-23, mar., 2015. Disponível em: <https://www.nature.com/news/developing-worldthe-minority-minority-1.17023>. Acesso em: 21 set. 2017.

MOZANS, H. J. Women in Science. New York; London: D. Appleton and Company, 1913. Disponível em: <https://archive.org/details/b24860670>. Acesso em: 28 out. 2017. 
NEALE, J. WHITE, K. The university environment: opportunities, constraints and challenges for senior women. Revista Ex æquo, Lisboa, n. 33, p. 67-81, 2016. Disponível em: $<$ http://exaequo.apem-estudos.org/artigo/33-the-university-environment-opportunitiesconstraints-and-chal>. Acesso em: 28 out. 2017.

PALHACI, M. do C. J. P. et al. Reflexão sobre a atuação de mulheres nas áreas de ciência e tecnologia. Intertech, Dili, Timor Leste, v. 11, n. 14, p. 120-123, 2012. Disponível em <https://repositorio.unesp.br/bitstream/handle/11449/134941/ISSN2317-4382-2012-12-120123.pdf?sequence=1>. Acesso em: 22 set. 2017.

PERROT, M. As mulheres ou o silêncio da História. Bauru: EDUSC, 2005.

. Escrever a história das mulheres. In: Minha História das Mulheres. São Paulo: Contexto, 2007.

Os excluídos da História: operários, mulheres e prisioneiros. Rio de Janeiro:

Paz e Terra, 2001.

PONTELO, A. das G. G. Relação de gênero em universidades mineiras: o fenômeno "teto de vidro" nos cargos da alta administração. 2015. 116f. Dissertação (Mestrado em Administração) - Faculdade Novos Horizontes, Belo Horizonte, 2015.

QUEIROZ, C. Uma mulher singular. Mary Shelley (1797-1851). Revista Ex æquo, Lisboa, n. 30, p.55-68, 2014. Disponível em: 〈http://www.scielo.mec.pt/pdf/aeq/n30/n30a05.pdf>. Acesso em: 25 abr. 2017.

REBIÈRE, A. Les femmes dans la Science: Conference Faite Au Cercle Saint-Simon, Le 24 Fevrier,1894. Paris, Librairie Nony \& Cie. 1897, p. IX. Disponível em: <https://archive.org/details/lesfemmesdanslas00rebiuoft>. Acesso em: 10 set. 2017.

ROSSI, A. "Women in Science: Why so few? Social and psychological influences restrict womens's choice and pursuit of careers in Science". Science, Washington, v. 148, issue 3674, p.1196-1202, may, 1965. Disponível em:

<http://science.sciencemag.org/content/148/3674/1196>. Acesso em: 30 nov. 2017.

SAFFIOTI, H.I.B. A mulher na sociedade de classes: mitos e realidade. Rio de Janeiro: Vozes, 1976. Disponível em: $<$ https://edisciplinas.usp.br/pluginfile.php/3825626/mod_resource/content/1/Saffioti\%20\%28 1978\%29\%20A_Mulher_na_Soc_Classes.pdf>. Acesso em: 03 de mar. 2018.

SANTOS, G. G.; CARVALHO, T. Introdução. Género, profissões e carreiras: Oportunidades, constrangimentos e desafios. Uma nota introdutória. Revista Ex æquo, Lisboa, n. 33, p. 1115, 2016. Disponível em: <http://www.scielo.mec.pt/pdf/aeq/n33/n33a02.pdf >. Acesso em: 10 set. 2017.

SARANT, L. Agentes of Change. Nature, Londres, set., p. 70-74, 2017. Disponível em: <https://www.nature.com/articles/549S70a.pdf>. Acesso em: 10 set. 2017. 


\section{\#tear}

SCOTT, J. Gênero: uma categoria útil para análise histórica. Educação e Realidade, Porto Alegre, v. 20, n. 2, p. 101-132, jul./dez., 1995. Disponível em:

<http://www.seer.ufrgs.br/index.php/educacaoerealidade/article/view/71721/40667>. Acesso: em: 10 set. 2017.

SHEN, H. Inequality quantified: Mind the gender gap. Nature, Londres, v. 495, n. 7, p. 22-24, mar., 2013. Disponível em:

<https://www.nature.com/polopoly_fs/1.12550!/menu/main/topColumns/topLeftColumn/pdf/ 495022a.pdf $>$. Acesso em: 13 set. 2017.

SCHIENBINGER, L. O feminismo mudou a ciência? Bauru: EDUSC, 2001. Disponível em: <http://brasil.indymedia.org/media/2007/06/386937.pdf>. Acesso em: 10 set. 2017.

Mais mulheres na ciência: questões de conhecimento. História, Ciências, Saúde Manguinhos, Rio de Janeiro: Fundação de Oswaldo Cruz, v. 15, supl., p. 269-281, jun., 2008. Disponível em: <http://www.scielo.br/pdf/hcsm/v15s0/15.pdf>. Acesso em: 05 maio 2017.

SCHIEBINGER, L.; SCHRAUDNER, M. Interdisciplinary Approaches to Achieving Gendered Innovations. Interdisciplinary Science Reviews: Taylor \& Francis, England, v. 36, n. 2, p.154-67, jun., 2011. Disponível em:

<https://genderedinnovations.stanford.edu/ISR_07_Schiebinger.pdf >. Acesso em: 13 set. 2017.

SOIHET, R. Mulheres e biografias. Significado para a história. Locus, Revista de História, Juiz de Fora, v. 9, n. 1, p. 27-42, 2003. Disponível em:

<https://locus.ufjf.emnuvens.com.br/locus/article/view/2469/1757>. Acesso em: 13 set. 2017.

História das mulheres. In: CARDOSO, C. F.; VAINFAS, R. Domínios da história: Ensaios de teoria e metodologia. Rio de Janeiro: Campus, 1997. p. 275-296.

SCHMITZ, G. A. P. D.; TRAMONTINA, R. Empoderamento feminino: uma análise a partir da teoria do poder simbólico de Pierre Bourdieu. Revista de Gênero, Sexualidade e Direito, Brasília, v. 3, n. 1, p. 98-107, jan./jun., 2017. Disponível em:

<http://www.indexlaw.org/index.php/revistagsd/article/view/1826>. Acesso em: 25 fev. 2018.

WANG, Y. The discourse of success by women scientists and technologists. Journal of Research in Education Sciences, Taiwan, v. 59, n. 4, p. 137-164, dez., 2014. Disponível em: $<$ http://jories.ntnu.edu.tw/jres/PaperContent.aspx?cid=189\&ItemId=1480\&loc=en\#> Acesso em: 10 set. 2017.

YANNOULAS, S. C. Trabalhadoras: análise da feminização das profissões e ocupações. Brasília: Editora Abaré, 2013. Disponível em:

<http://www.oitcinterfor.org/sites/default/files/file_publicacion/trabalhadoras.pdf >. Acesso em: 13 set. 2017. 